\title{
An assessment on the use of bivariate, multivariate and soft computing techniques for collapse susceptibility in GIS environ
}

\author{
Işik Yilmaz ${ }^{1, *}$, Marian Marschalko ${ }^{2}$ and Martin Bednarik ${ }^{3}$ \\ ${ }^{1}$ Department of Geological Engineering, Cumhuriyet University, 58140 Sivas, Turkey. \\ ${ }^{2}$ Institute of Geological Engineering, VS̆B-Technical University of Ostrava, \\ 17. listopadu 15, 70833 Ostrava, Czech Republic. \\ ${ }^{3}$ Department of Engineering Geology, Comenius University, Mlynská dolina, \\ 842 15 Bratislava, Slovak Republic. \\ ${ }^{*}$ Corresponding author.e-mail: iyilmaz@cumhuriyet.edu.tr
}

\begin{abstract}
The paper presented herein compares and discusses the use of bivariate, multivariate and soft computing techniques for collapse susceptibility modelling. Conditional probability (CP), logistic regression (LR) and artificial neural networks (ANN) models representing the bivariate, multivariate and soft computing techniques were used in GIS based collapse susceptibility mapping in an area from Sivas basin (Turkey). Collapse-related factors, directly or indirectly related to the causes of collapse occurrence, such as distance from faults, slope angle and aspect, topographical elevation, distance from drainage, topographic wetness index (TWI), stream power index (SPI), Normalized Difference Vegetation Index (NDVI) by means of vegetation cover, distance from roads and settlements were used in the collapse susceptibility analyses. In the last stage of the analyses, collapse susceptibility maps were produced from the models, and they were then compared by means of their validations. However, Area Under Curve (AUC) values obtained from all three models showed that the map obtained from soft computing (ANN) model looks like more accurate than the other models, accuracies of all three models can be evaluated relatively similar. The results also showed that the conditional probability is an essential method in preparation of collapse susceptibility map and highly compatible with GIS operating features.
\end{abstract}

\section{Introduction}

Collapse structures in gypsum terrains are serious geological hazards because they can damage engineering structures, produce settlement areas, form natural lakes and allow infiltration of contaminant into the groundwater. Presentation of engineering geological data in the form of a hazard map is a useful tool in urban planning. There have been few studies carried out on collapse hazard and/or susceptibility mapping, such as Forth et al. (1999), Tolmachev et al. (1999), Kaufman and Quinif (2002), Zhou et al. (2003), Yilmaz (2007), Bruno et al. (2008), Guerrero et al. (2008), Galve et al. (2008).

Forth et al. (1999) had produced a map showing relative risk of hazard occurrence along the coast of the Algarve (Portugal). They had taken into consideration of sinkholes, caving, gullying, slope angle, tension cracks, fissuring, rock falls,

Keywords. Collapse susceptibility map; gypsum; GIS; bivariate (conditional probability); multivariate (logistic regression); soft computing (artificial neural networks). 
mechanical strength and vegetation cover as controlling factors. Selected sizes of cells unfortunately were $100 \mathrm{~m}^{2}$ in a quitely small study area $\left(<1 \mathrm{~km}^{2}\right)$, and so they obtained a very rough map. Tolmachev et al. (1999) prepared a sinkhole hazard zonation for a $25 \mathrm{~km}$ long section of the Moscow-Nizhny Novgorod high-speed line based on the spatio-temporal frequency of sinkholes in the railway right-of-way. Kaufman and Quinif (2002) reported a methodology for drawing geo-hazard map of cover collapse sinkhole occurrences in limestones overlained by a Mesocenozoic cover consisting of marls, sand and clay in the 'Tournaisis' area (Belgium). They used parameters such as the dewatering of limestone, thickness of cover formation, density of former collapses. They found that zones of high sinkhole occurrence coincide with the zones of heavy lowering of piezometric heads. They delineated the zones of low, moderate and high collapse hazard by combining the density of former collapses with the dewatering of the limestone. Zhou et al. (2003) presented a sinkhole susceptibility zonation for the Maryland interstate highway I-70 based on spatial distribution analyses of recorded sinkholes and the application of a scoring system to several controlling factors. The probabilistic method for assessment of collapse susceptibility was first used by Yilmaz (2007), and he took into account the collapse factors, directly or indirectly related to the causes of collapse occurrences in a given region, such as lithology, drainage system, structural lineaments (such as faults and folds), morphology (slope angle, slope aspect, elevation), springs, roads, settlement areas and vegetation cover, etc., in order to produce collapse susceptibility map in gypsum terrain in Sivas basin (Turkey). Higher quality of the map by means of its performance had been obtained and the map was considered as satisfactory. Bruno et al. (2008) explained the development of sinkholes in coastal plains selected from southern Italy and proposed a method for producing a collapse susceptibility map in karst terrains in their paper. The susceptibility map had unfortunately roughly drawn using cells having a dimension $62.5 \times 62.5 \mathrm{~m}$ in $\sim 2 \mathrm{~km}^{2}$ study area as discussed by Yilmaz (2008a). Guerrero et al. (2008) presented a methodology for producing sinkhole susceptibility zonations along linear infrastructures based on the analysis of the subsidence and dissolution features exposed in the adjacent cuttings and the distribution of karstic depressions along the stretch of high-speed Madrid-Barcelona railway built on halite- and glauberite-bearing evaporites of the Tertiary Zaragoza Gypsum Formation in Spain. They discussed that the approach described in their paper, based on analysis of dissolution features and subsidence structures exposed in the railway cuttings, may constitute a highly useful and inexpensive method to produce sinkhole susceptibility zonations and to identify particularly dangerous points. Galve et al. (2008) carried out the analysis of sinkhole susceptibility in a stretch $50 \mathrm{~km}^{2}$ in area of the Ebro valley alluvial evaporite karst (NE Spain). They used thematic maps of sinkholes, topography, geomorphology, geology, hydrogeology, hydro-geochemistry and human structures in their analysis and found that $\sim 75 \%$ of the sinkholes occur on the $10 \%$ of the pixels with the highest susceptibility according to validation curves.

In this paper, collapse susceptibility maps of a selected area in Sivas basin (Turkey) were prepared by use of bivariate - conditional probability (CP), multivariate - logistic regression (LR) and soft computing - artificial neural networks (ANN) models. At the end of the study, the maps obtained from four models were then compared according to their validation degrees. This paper will also add an extra value to the literature of the collapse susceptibility mapping as a comparative study of very basic techniques (CP) with both statistical (LR) and soft computing techniques (ANN).

\section{Study area}

Gypsum provides actual numbers of coverage, and is extensively karstified with numerous sinkholes, dolines and other depressions (figures 1 and 2), and the entire area in the region is composed of gypsum. Collapse structures were generally classified as cover collapse based on their genesis. They were formed by the failure of the rock roof of an underlying cave and characterized by steep walls and large voids in the rock beneath.

Depressions in the study area are especially observed as a form of doline. Dolines have been subdivided into three groups by Karacan and Yilmaz (1997). The first group comprises partially collapsed dolines; the second group appears to develop together with cracks on the surface; the third group comprises olders (Karacan and Yilmaz 1997; Yilmaz and Karacan 2005). The first two groups of dolines are very young, while the others are older.

In the region, urbanization is developing towards east of Sivas city, and the study area is especially valuable for sites of plants and waste disposal. In order to produce a collapse susceptibility map, which will also serve to regional planning, 1:25,000 scaled map was chosen. Collapses in the gypsum terrains in Sivas basin are a current problem where they can cause extensive damage to property.

Hafik Lake to the east of Sivas, Tödürge Lake to the west of Zara and Ulas Lake to the south 


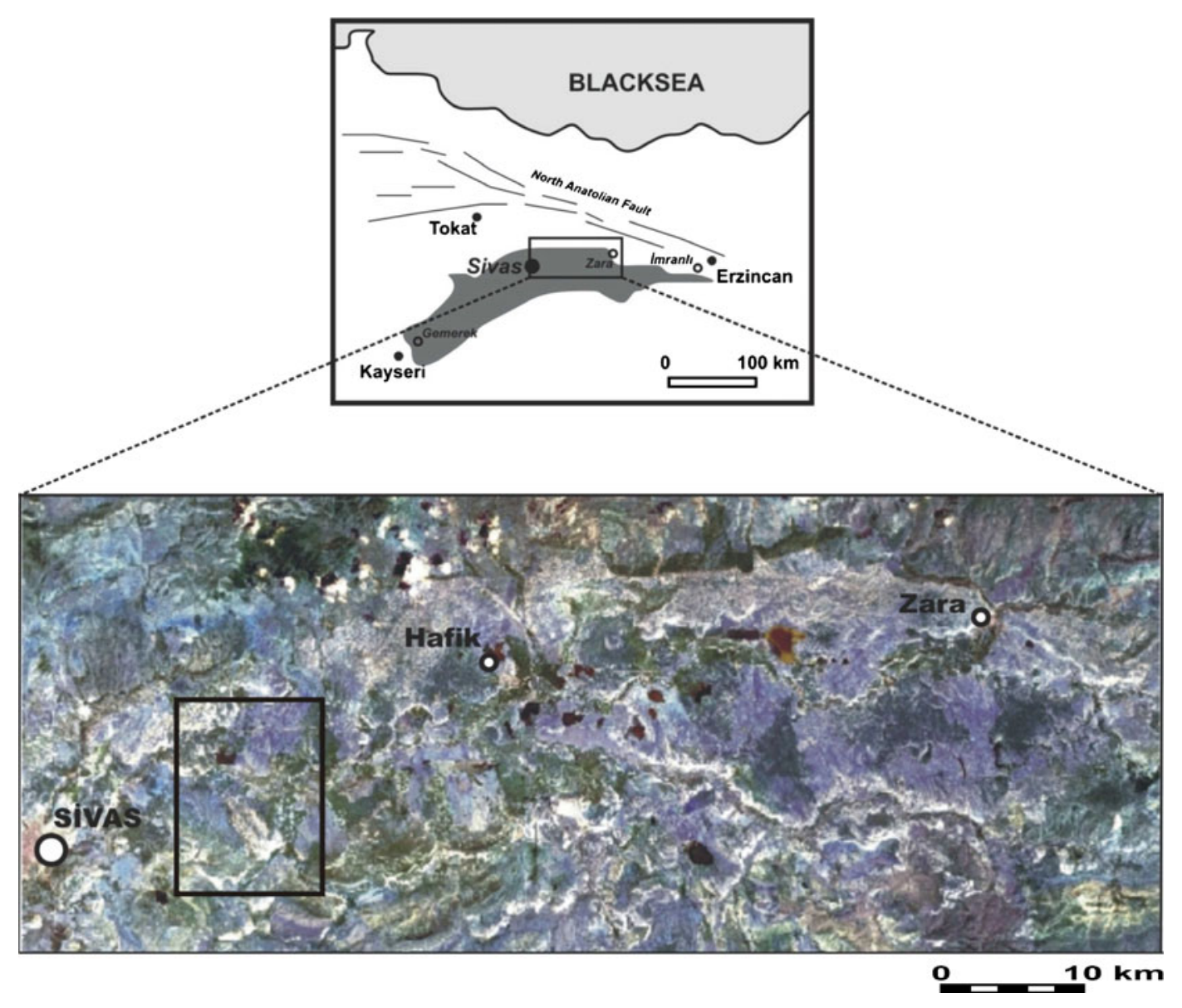

Figure 1. Location map of the case study area.

of Sivas have filled karst depressions. Most of the sinkholes have been formed along faults, and groundwater discharge to the river can be observed in some places (Karacan and Yilmaz 1997). In addition, dolines and collapse passages play an important role in the groundwater flow system (Karacan and Yilmaz 1997).

\section{Susceptibility mapping}

An understanding of the karst breakdown mechanism is crucial for assessment, prediction and management of subsidence hazards in karst terrains. A set of component agencies and a shifting of the breakdown process proper (i.e., breakdown mechanism) depends on many factors and conditions. The most important factors can be considered as the presence and structure of overburden, lithological properties of individual units in the cover, hydrogeological conditions such as piezometric levels and hydraulic gradients, degree of karstification and characteristics of the primitive initiating cavities (Klimchouk and Andrejchuk 2005).

As stated by Yilmaz (2007), interpretation of future collapse occurrence requires an understanding of conditions and processes controlling collapse event. In order to predict collapse, it is necessary to assume that collapse occurrence is determined by collapse-related factors, and that future collapses will occur under the same conditions as past collapses. On this basis, the relationship between areas where a collapse has occurred and collapserelated factors can be distinguished from the relationship between areas without past collapses and collapse-related factors. The evidence of collapse structures such as dolines and sinkholes is the most important factor in the prediction of future collapses.

Preparation of the karst inventory map, which presents karst affected area, is the first primary goal for assessment of the hazard and vulnerability in a given area. A karst inventory map should provide data for hazard and vulnerability mapping and assist to landscape level planning. However, preparation of the karst inventory requires significant amount of field works, satellite imagery and other remote sensing data, including recent and historical air photos, surficial and bedrock geological maps and detailed topographic information, etc., that will provide useful data in order to facilitate and complete data for inventory mapping. 


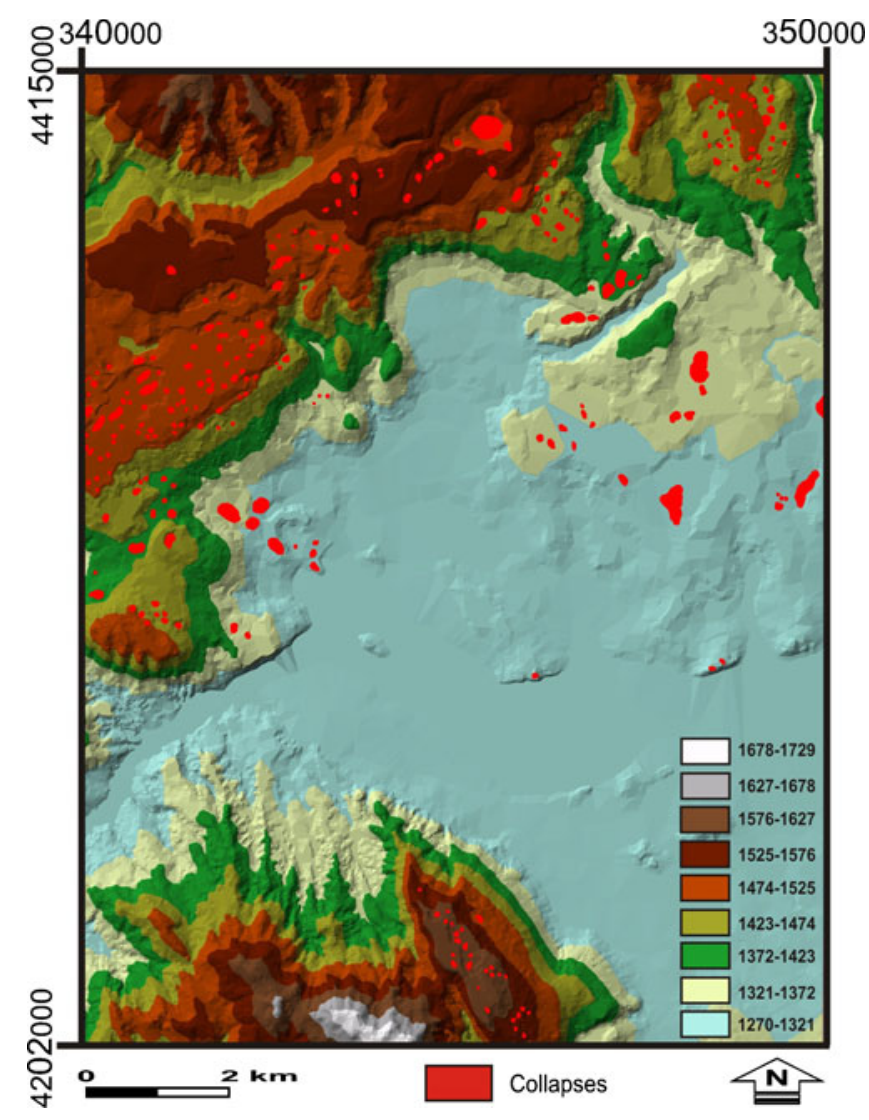

Figure 2. Distribution of the collapse structures on the DEM of study area.

Attributes and descriptions in the content of karst inventory preparation should include polygons corresponding to boundaries of karst structure. The database of collapse-related factors such as, geological, hydrological, topographical, environmental, surficial material was obtained, and both inventory and collapse-related factors were then inserted to GIS environ in a GIS software of ArcGIS 9.1. Hazard and susceptibility maps were constructed by using statistical and/or soft computing techniques (figure 3 ).

\subsection{Database used in the models}

Point data in GIS can be described by a single $(\mathrm{X}, \mathrm{Y})$ coordinate and does not reflect the collapse affected area, and this type of feature may be used when the areal extend of a small collapse cannot be drawn due to the scale of the map. However, the logic way is to reveal the collapse responsible pixels. In the study area, collapses were only observed if they were larger than one cell $(10 \times 10 \mathrm{~m})$ used in the analyses. In collapse inventory mapping, for each surficial collapse zone as polygon feature drawn from Landsat TM satellite images (May 2006), 1:35,000 aerial photographs, field work, and converted to the raster format (figure 2).

As discussed by Yilmaz (2009), capability of cell numbers depends on the cell size and resolution used in the analyses. Digital elevation models (DEM) (figure 2) having a resolution of 1353 rows and 1037 columns, and totally 14,03,061 cells $(10 \times 10 \mathrm{~m})$ enclosing a rectangle of $\sim 140.3 \mathrm{~km}^{2}$ was first implemented from 1:25,000 scaled topographic maps, and slope angle, slope aspect and topographical elevation maps were then produced from the DEM. Collapse-affected factors, directly or indirectly related to the causes of collapse occurrence in a given region, such as distance from faults, slope angle and aspect, topographical elevation, distance from drainage, topographic wetness index (TWI), stream power index (SPI), normalized difference vegetation index (NDVI) by means of vegetation cover, distance from roads and settlements (figures 4, 5, 6 and 7) parameters, were obtained. Topographic wetness index and stream power index are the second derivatives of the digital elevation models indirectly describing

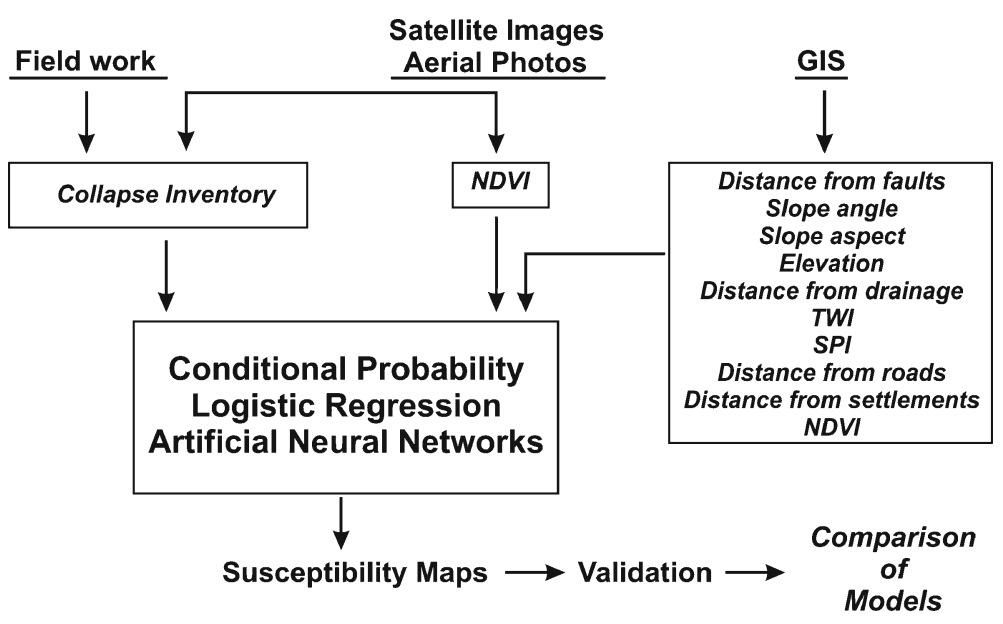

Figure 3. Flowchart of the works for production of collapse susceptibility maps. 

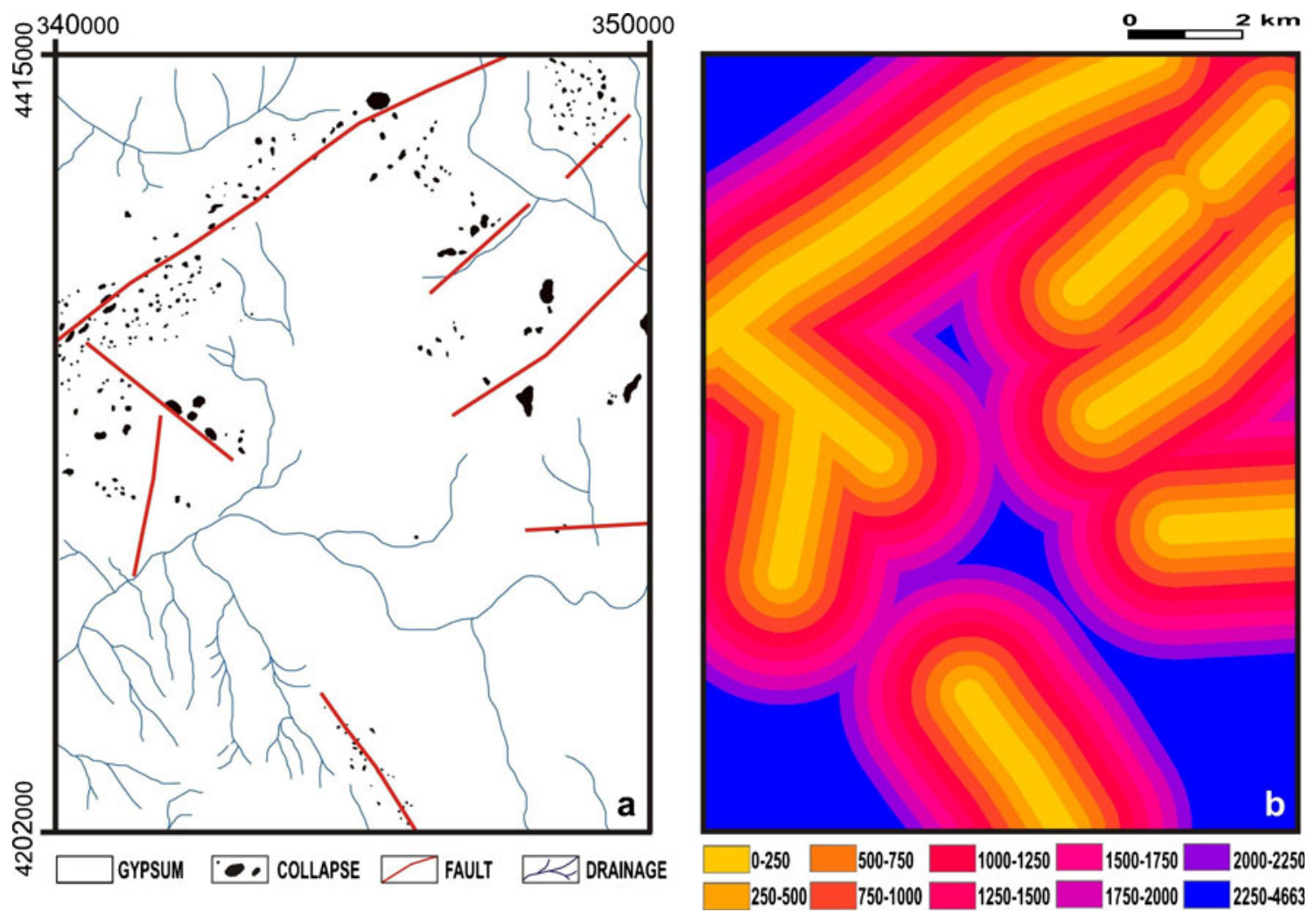

Figure 4. Collapse-related geological factor maps: (a) geological map and (b) distance from faults.
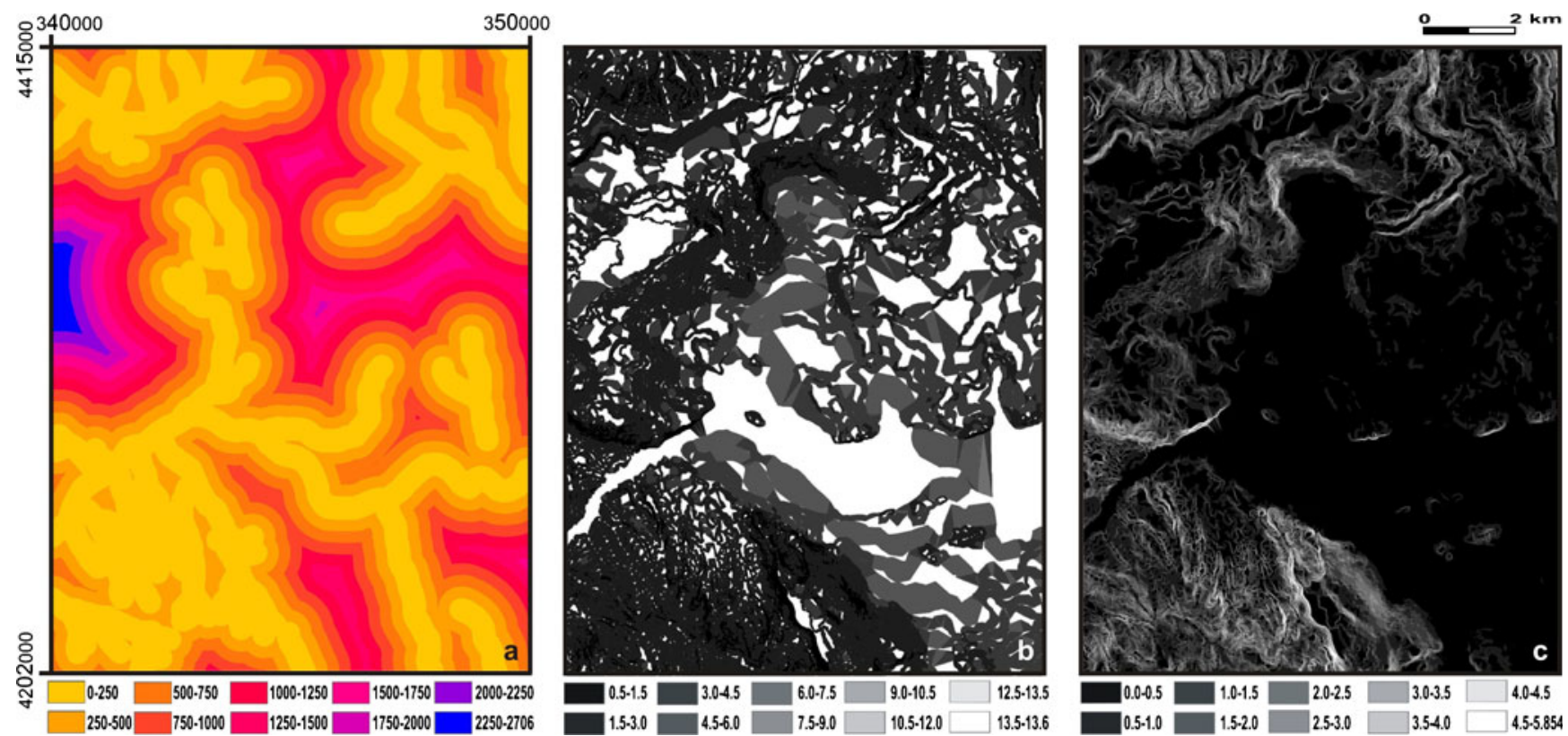

Figure 5. Collapse-related hydrological factor maps: (a) distance from drainage, (b) SPI and (c) TWI.

the hydrological situation of the relevant terrain (Wilson and Gallant 2000). The theoretical background of the parameters could be found in Nefeslioglu et al. (2012).

In order to understand the significance of the selected factors, frequency ratios of each factor were calculated and the variables were included in the model. The frequency ratio method is very easy to apply, and results obtained by Lee and Talib (2005), Lee and Sambath (2006), Lee and TuDan (2005) and Yilmaz (2007) are very intelligible. The frequency ratio, which was calculated 

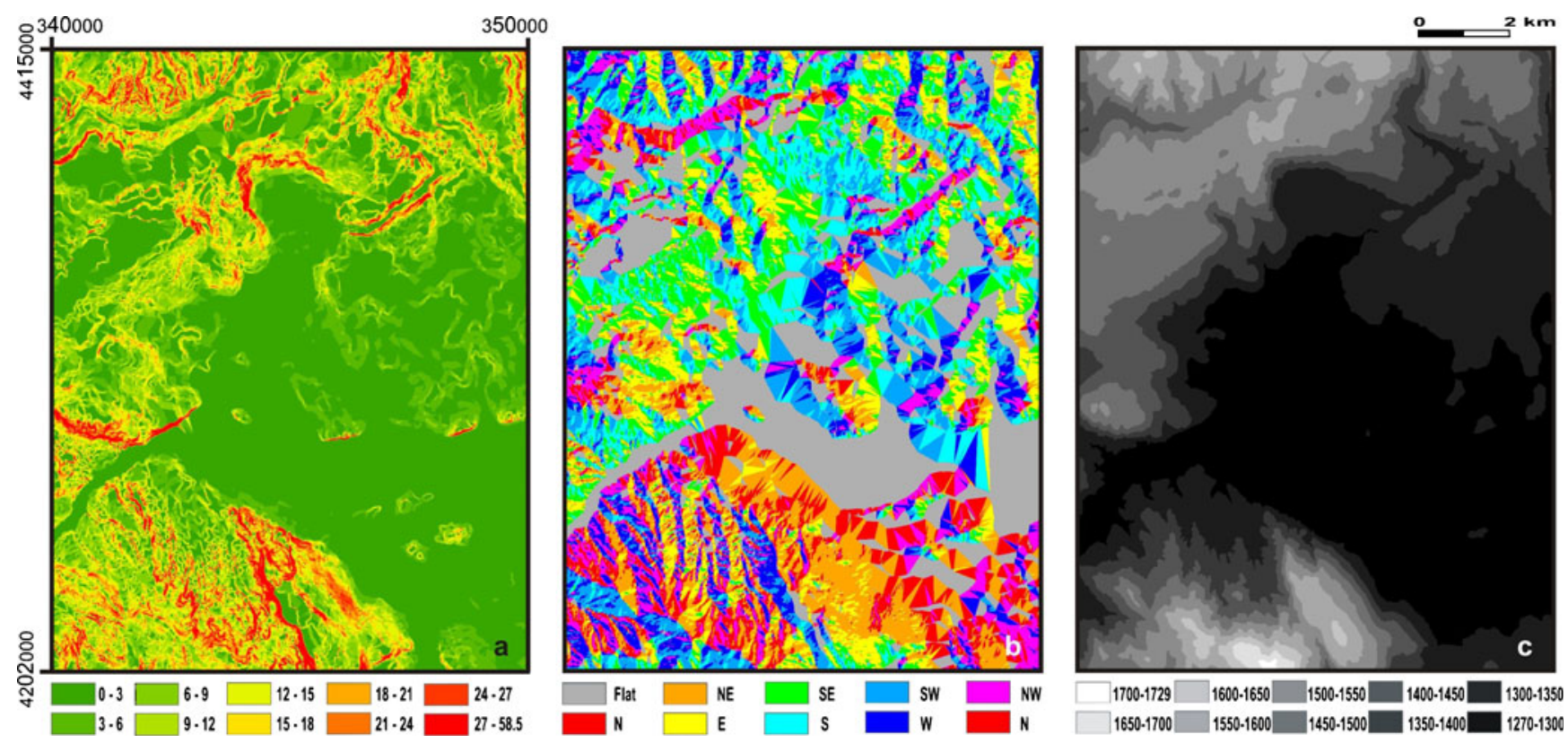

Figure 6. Collapse-related topographical factor maps: (a) slope gradient, (b) slope aspect and (c) topographical elevation.
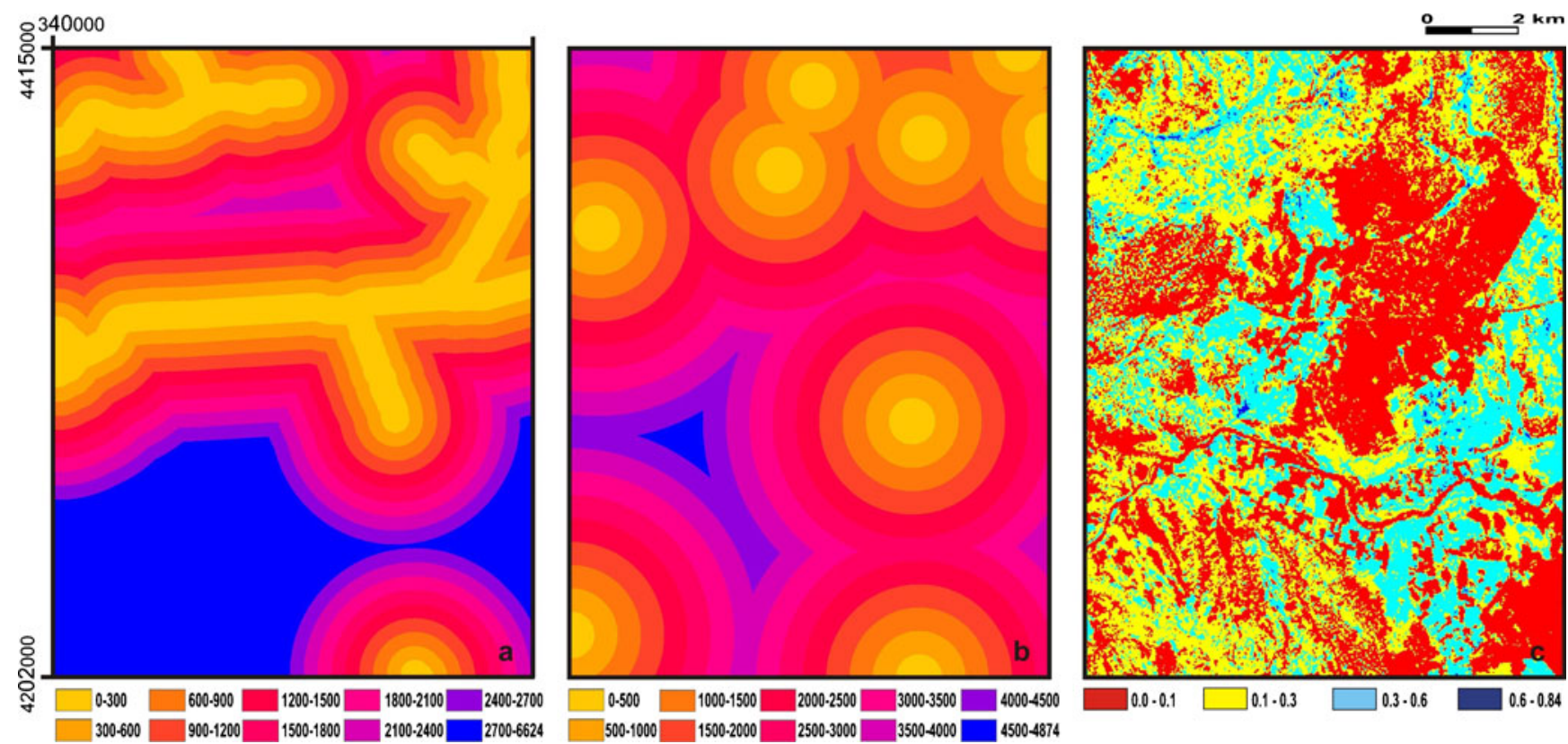

Figure 7. Collapse-related land-use and vegetation cover factor maps: (a) distance from roads, (b) distance from settlements and (c) NDVI.

as the ratio of the probabilities of a collapse occurrence to a non-occurrence for a given attribute, was used to obtain relationships between collapserelated factors chosen and collapse occurrence area. Frequency ratio values greater than 1 indicate a high probability of collapse occurrence. In order to find the relationships between collapserelated factors chosen and collapse occurred area, graphs of the probabilities of a collapse occurrence versus classes of given attribute were drawn and significant factors were considered in the collapse susceptibility analyses (figures 8-11). All of the selected factors were found to be significant in assessment of collapse susceptibility.

\subsection{Models}

In this study, three different models (bivariate, multivariate and soft computing) were applied in 


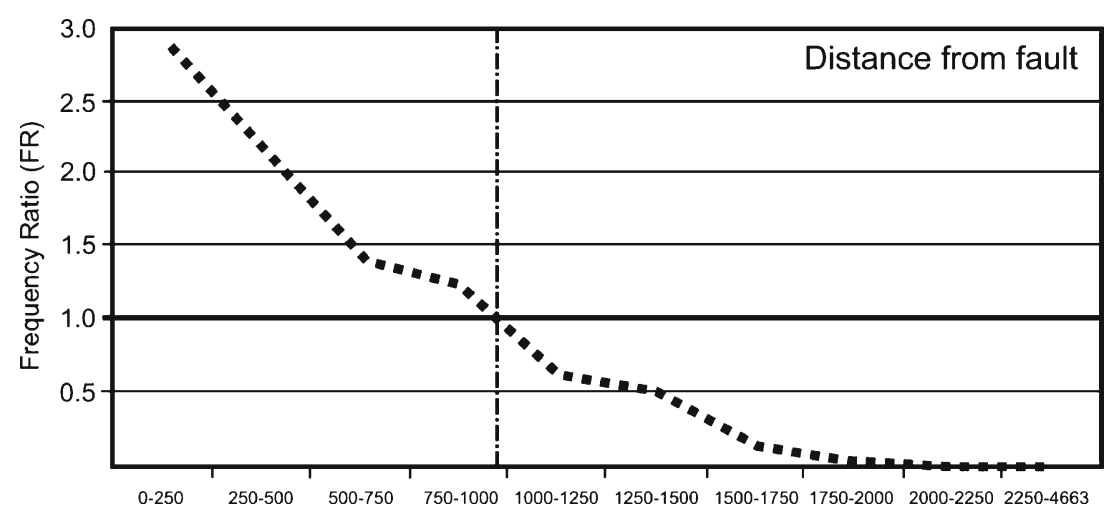

Figure 8. Relationships between collapse-related geological factors and collapse occurrence.
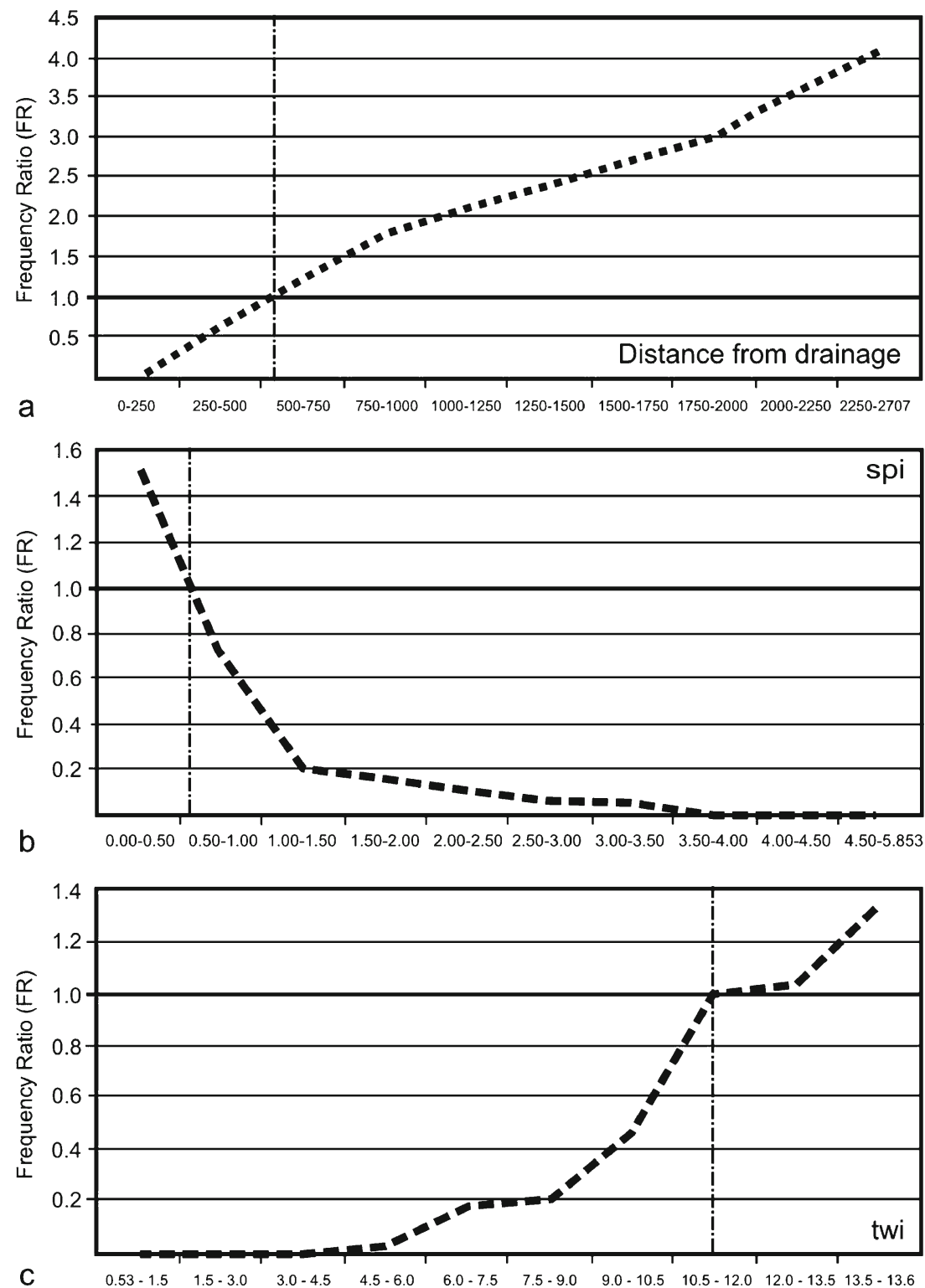

Figure 9. Relationships between collapse-related hydrological factors: (a) distance from drainage, (b) SPI and (c) TWI and collapse occurrence. 

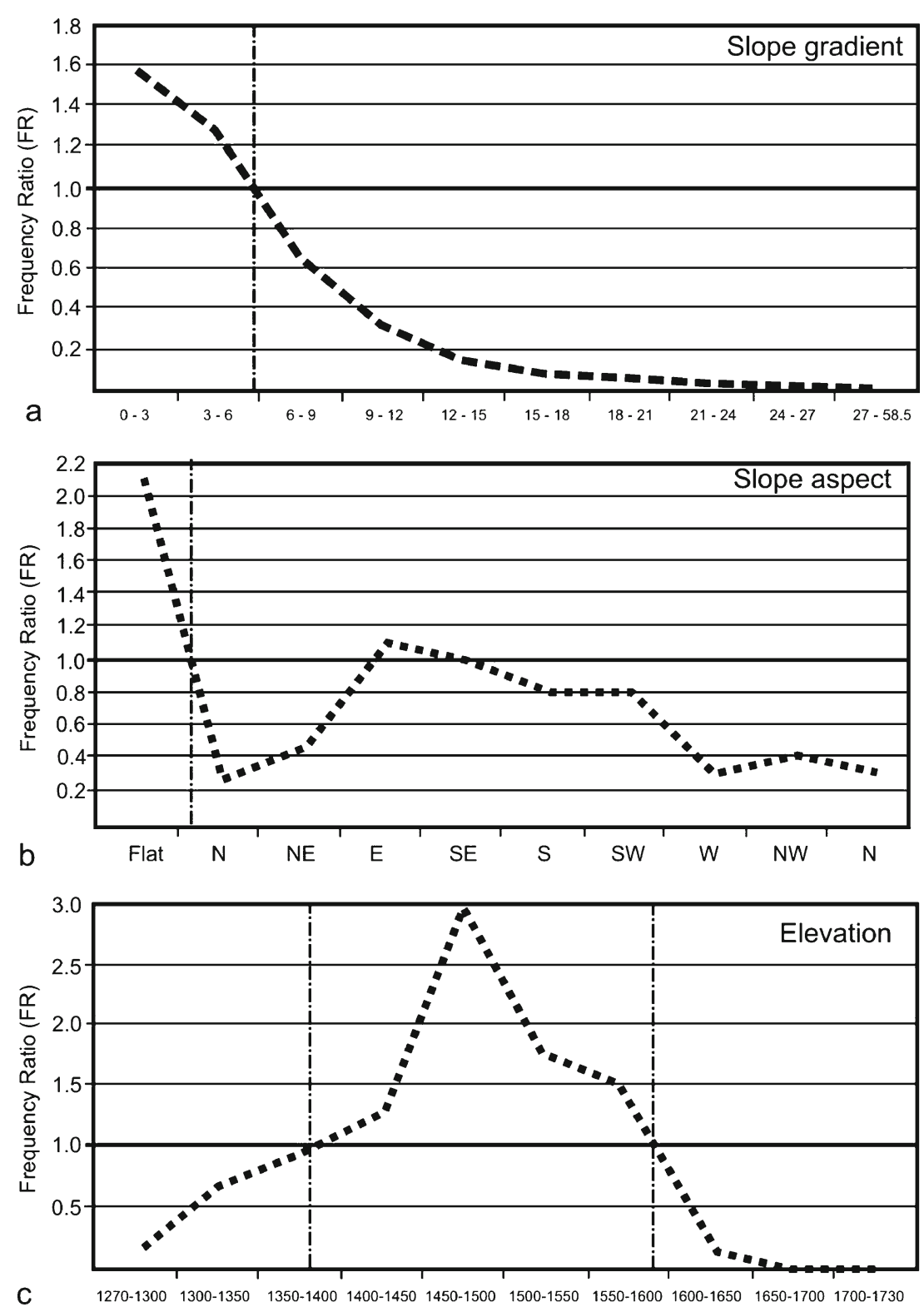

Figure 10. Relationships between collapse-related topographical factors: (a) slope gradient, (b) slope aspect and (c) topographical elevation and collapse occurrence.

gypsum terrain for assessment of collapses by means of collapse susceptibility. Models used in the article consist of basic conditional probability $(\mathrm{CP})$, complicated statistical method of logistic regression (LR) and more sophisticated artificial neural network (ANN) as a soft computing method.

Conditional probability is one of the basic bivariate methods for producing a susceptibility map and highly compatible with GIS (Ramakrishnan et al. 2005). Non-specialists can also produce the maps easily. Number of factors related to occurrences can be considered in the conditional probability approach.

Logistic regression, which is a multivariate analysis model, is useful for predicting the presence or absence of a characteristic or outcome based on values of a set of predictor variables. The advantage of logistic regression is that, through the addition of an appropriate link function to the usual linear regression model, the variables may be either continuous or discrete, or any combination of both types, and they do not necessarily have normal distributions (Menard 1995).

The use of ANNs, which is very well-known soft computing method is an alternative method for susceptibility mapping and risk zonation. Because, ANNs, with their remarkable ability to derive meaning from complicated or imprecise data, can be used to extract patterns and detect trends that are too complex to be noticed by either humans or other computer techniques. Trained neural networks can be thought of as an 'expert' in the 

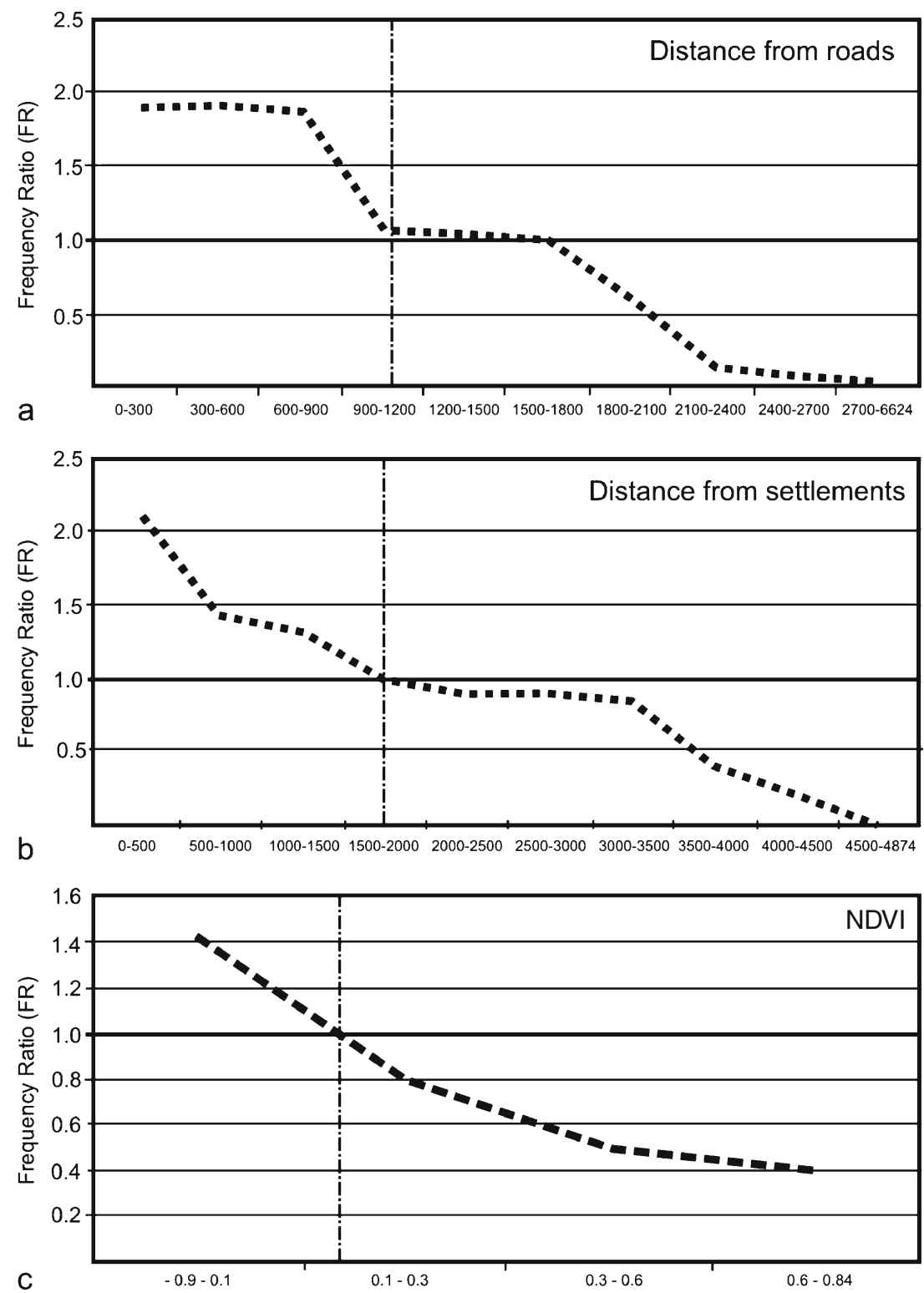

Figure 11. Relationships between collapse-related land-use and vegetation cover factors: (a) distance from roads, (b) distance from settlements and (c) NDVI and collapse occurrence.

category of information it has been given to analyse. This expert can then be used to provide projections given new situations of interest and answer 'what if' questions. Other advantages include: adaptive learning, self-organization, realtime operation and fault tolerance via redundant information coding (Singh et al. 2003).

\subsubsection{Bivariate model - conditional probability}

Conditional probability is one of the basic methods for producing a susceptibility map and highly compatible with GIS. Number of factors related to occurrences can be considered in the conditional probability approach. The data layers containing each factor subdivided into a convenient number of classes are crossed in order to obtain possible combinations of the various classes of the different factors (Clerici et al. 2002). Each specific combination represents a pixel, and the collapse spatial frequency is subsequently determined within each pixel. The resulting collapse density equals the collapse susceptibility, assuming that the collapse in future will be more likely occurred under those conditions which led to the past instability and frequency of an event equals the probability that the same event will occur (Clerici et al. 2002).

In order to categorize the conditioning factors, the quantile method was used. In this method, every $10 \%$ fraction of the relevant factor assigned as different parameter subclass, and then, the collapse distribution was evaluated by using these subclasses of the conditioning factors. 
Conditional probability is denoted mathematically as $P(A \mid B)$ (equation 1) (Negnevitsky 2002; Gokceoglu et al. 2005).

$$
\begin{aligned}
P & (A \mid B) \\
= & \frac{\text { (the number of times } A \text { and } B \text { can occur) }}{\text { (the number of times } B \text { can occur) }}
\end{aligned}
$$

The number of times $A$ and $B$ can occur, or the probability that both $A$ and $B$ will occur, is also called 'joint probability' of $A$ and $B$. It represents mathematically as $P(A \cap B)$. The number of ways $B$ can occur is the probability of $B, P(B)$ :

$$
\begin{gathered}
P(A \mid B)=P(A \cap B) / P(B) \\
P(B \mid A)=P(B \cap A) / P(A) \\
P(B \cap A)=P(B \mid A) \times P(A) \\
P(A \cap B)=P(B \cap A)
\end{gathered}
$$

Bayesian rule is given in equation (6) and equation (7) can be written as event $A$ being dependent on a number of mutually exclusive events $B_{1}$, $B_{2}, \ldots, B_{n}$.

$$
P(A \mid B)=[P(B \mid A) \times P(A)] / P(B)
$$

By using equation (5), we can derive the following conditional probability equations for different thematic layer:

$$
\begin{aligned}
& P\left(A \cap B_{1}\right)=P\left(A \mid B_{1}\right) \times P\left(B_{1}\right) \\
& P\left(A \cap B_{2}\right)=P\left(A \mid B_{2}\right) \times P\left(B_{2}\right) \\
& : \\
& P\left(A \cap B_{n}\right)=P\left(A \mid B_{n}\right) \times P\left(B_{n}\right)
\end{aligned}
$$

Then, we can combine the equations and write the final conditional probability equation for each mapping unit (equation 7).

$$
P(A)=\sum_{i=1}^{n} P(A \cap B)=\sum_{i=1}^{n} P\left(A \mid B_{i}\right) * P\left(B_{i}\right)
$$

The mapping unit in the present study is the grid cell. So, each spatial domain in study area corresponds to a unique grid cell in the present research. This means that every grid cells have their own information on ' $n$ ' conditioning factors. Obviously, as it can be clearly realized that each spatial domain contains only one subclass for each conditioning factor and each subclass has its own conditional probability value. Therefore, the total conditional probability for each spatial domain in the study area is the summation of ' $n$ ' conditional probability values on each grid cell.

Collapse susceptibility maps were then produced using equation (7) for study area (figure 12a). The $P(A \mid B), P(A)$ and $P(B)$ values are tabulated in tables 1-4.

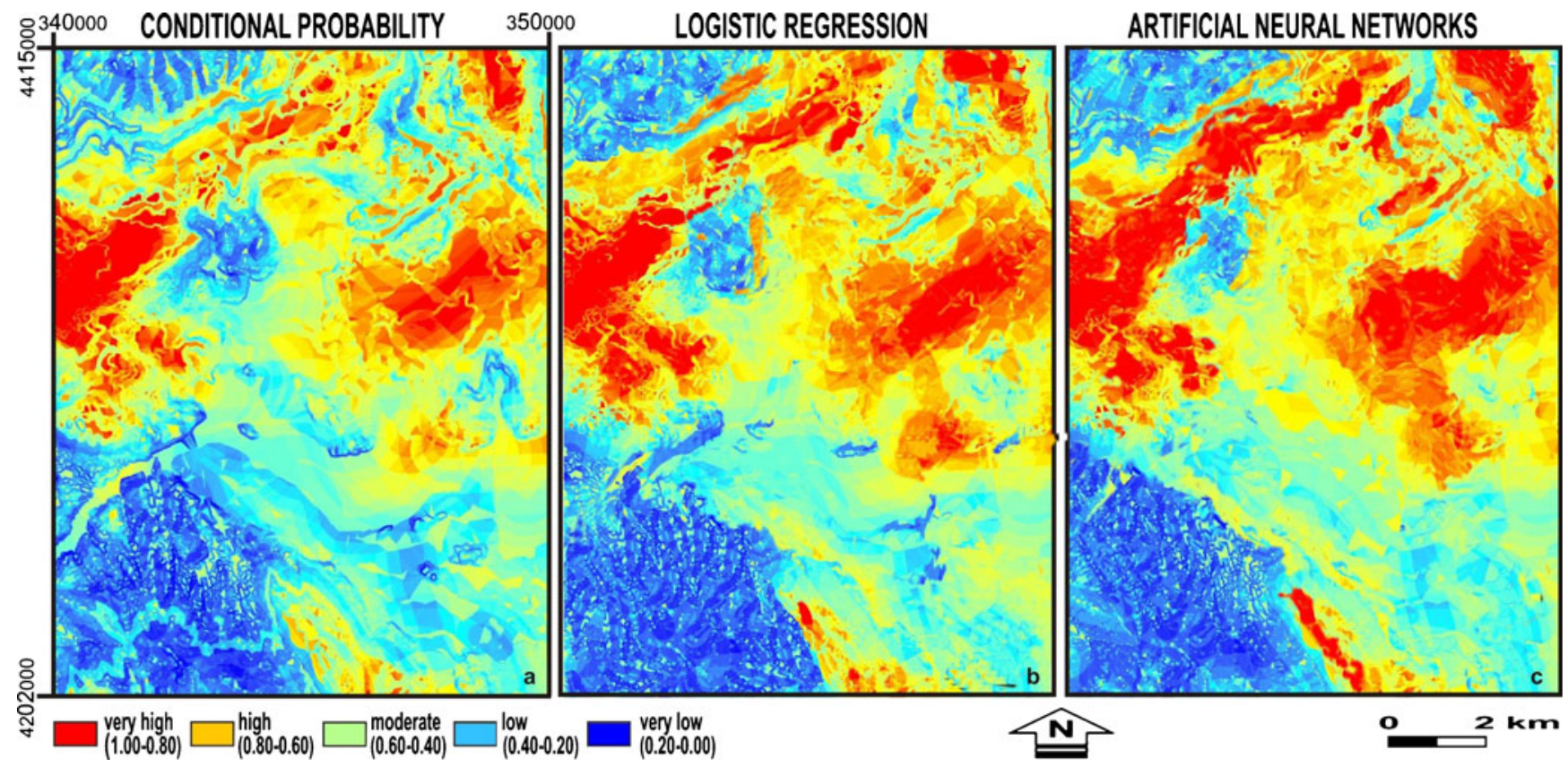

Figure 12. Collapse susceptibility maps produced from conditional probability CP (a), Logistic Regression - LR (b), artificial neural networks - ANN (c) models. 
Table 1. Frequency ratio of geological factors to collapse occurrences and results of the $P\left(A / B_{i}\right)$ obtained from the Conditional Probability model.

\begin{tabular}{|c|c|c|c|c|c|c|}
\hline Class & $\mathrm{CA}(\%)$ & Grid (\%) & FR & $P(A)$ & $P\left(B_{i}\right)$ & $P\left(A / B_{i}\right)$ \\
\hline \multicolumn{7}{|c|}{ Distance from faults } \\
\hline $0-250$ & 31.54725 & 11.14442 & 0.001756 & 0.01422 & 0.433095 & 0.032834 \\
\hline $250-500$ & 25.24886 & 11.6166 & 0.005384 & 0.011381 & 0.451445 & 0.02521 \\
\hline $500-750$ & 15.90881 & 11.97382 & 0.007036 & 0.007171 & 0.465328 & 0.015411 \\
\hline $750-1000$ & 15.23289 & 12.25342 & 0.010251 & 0.006866 & 0.476194 & 0.014419 \\
\hline $1000-1250$ & 6.329114 & 10.69733 & 0.012751 & 0.002853 & 0.41572 & 0.006863 \\
\hline $1250-1500$ & 4.504117 & 9.04558 & 0.022483 & 0.00203 & 0.35153 & 0.005776 \\
\hline $1500-1750$ & 0.989308 & 7.607795 & 0.021906 & 0.000446 & 0.295655 & 0.001508 \\
\hline $1750-2000$ & 0.239646 & 6.766064 & 0.020009 & 0.000108 & 0.262943 & 0.000411 \\
\hline $2000-2250$ & 0 & 5.368904 & 0.005104 & 0 & 0.208647 & 0 \\
\hline $2250-4663$ & 0 & 13.52607 & 0.00021 & 0 & 0.525651 & 0 \\
\hline
\end{tabular}

CA: collapse affected grid percent, Grid (\%): grids in domain percent, FR: collapse affected grid $(\%) /$ grids $(\%)$.

Table 2. Frequency ratio of hydrological factors to collapse occurrences and results of the $P\left(A / B_{i}\right)$ obtained from the Conditional Probability model.

\begin{tabular}{|c|c|c|c|c|c|c|}
\hline Class & CA $(\%)$ & Grid $(\%)$ & $\mathrm{FR}$ & $P(A)$ & $P\left(B_{i}\right)$ & $P\left(A / B_{i}\right)$ \\
\hline \multicolumn{7}{|c|}{ Distance from drainage } \\
\hline $0-250$ & 1.149072 & 33.21288 & 0.034597 & 0.000518 & 1.290722 & 0.000401 \\
\hline $250-500$ & 14.97481 & 21.58124 & 0.693881 & 0.00675 & 0.838692 & 0.008048 \\
\hline $500-750$ & 18.85216 & 15.26092 & 1.235323 & 0.008498 & 0.593071 & 0.014328 \\
\hline $750-1000$ & 19.71857 & 11.34491 & 1.738098 & 0.008888 & 0.440887 & 0.02016 \\
\hline $1000-1250$ & 17.37741 & 8.261793 & 2.103346 & 0.007833 & 0.32107 & 0.024397 \\
\hline $1250-1500$ & 13.02077 & 5.43754 & 2.394607 & 0.005869 & 0.211314 & 0.027775 \\
\hline $1500-1750$ & 6.507312 & 2.420921 & 2.687949 & 0.002933 & 0.094082 & 0.031177 \\
\hline $1750-2000$ & 3.170702 & 1.053482 & 3.009734 & 0.001429 & 0.040941 & 0.03491 \\
\hline $2000-2250$ & 2.525501 & 0.762618 & 3.311618 & 0.001138 & 0.029637 & 0.038411 \\
\hline $2250-2707$ & 2.703699 & 0.663692 & 4.073727 & 0.001219 & 0.025792 & 0.047251 \\
\hline \multicolumn{7}{|l|}{ SPI } \\
\hline $0-0.5$ & 84.08504 & 55.6469 & 1.511046 & 0.037902 & 2.162554 & 0.017527 \\
\hline $0.5-1.0$ & 11.97001 & 16.66371 & 0.718328 & 0.005396 & 0.647586 & 0.008332 \\
\hline $1.0-1.5$ & 2.292 & 12.53324 & 0.182874 & 0.001033 & 0.487068 & 0.002121 \\
\hline $1.5-2.0$ & 1.118348 & 7.723755 & 0.144793 & 0.000504 & 0.300161 & 0.001679 \\
\hline $2.0-2.5$ & 0.4117 & 4.227471 & 0.097387 & 0.000186 & 0.164288 & 0.00113 \\
\hline $2.5-3.0$ & 0.092172 & 1.865421 & 0.049411 & $4.15 \mathrm{E}-05$ & 0.072494 & 0.000573 \\
\hline $3.0-3.5$ & 0.030724 & 0.747508 & 0.041102 & $1.38 \mathrm{E}-05$ & 0.02905 & 0.000477 \\
\hline $3.5-4.0$ & 0 & 0.323578 & 0 & 0 & 0.012575 & 0 \\
\hline $4.0-4.5$ & 0 & 0.161789 & 0 & 0 & 0.006287 & 0 \\
\hline $4.5-5.853$ & 0 & 0.106624 & 0 & 0 & 0.004144 & 0 \\
\hline \multicolumn{7}{|l|}{ TWI } \\
\hline $0.53-1.5$ & 0 & 0.007056 & 0 & 0 & 0.000274 & 0 \\
\hline $1.5-3.0$ & 0 & 0.031004 & 0 & 0 & 0.001205 & 0 \\
\hline $3.0-4.5$ & 0 & 0.227859 & 0 & 0 & 0.008855 & 0 \\
\hline $4.5-6.0$ & 0.030724 & 0.77281 & 0.039756 & $1.38 \mathrm{E}-05$ & 0.030033 & 0.000461 \\
\hline $6.0-7.5$ & 0.184343 & 0.948498 & 0.194353 & $8.31 \mathrm{E}-05$ & 0.036861 & 0.002254 \\
\hline $7.5-9.0$ & 0.755807 & 3.818009 & 0.197958 & 0.000341 & 0.148376 & 0.002296 \\
\hline $9.0-10.5$ & 3.133833 & 7.243092 & 0.432665 & 0.001413 & 0.281482 & 0.005018 \\
\hline $10.5-12$ & 31.94052 & 31.86547 & 1.002355 & 0.014397 & 1.238359 & 0.011626 \\
\hline $12-13.5$ & 29.63623 & 29.04271 & 1.020436 & 0.013359 & 1.12866 & 0.011836 \\
\hline $13.5-13.6$ & 34.31854 & 26.04349 & 1.31774 & 0.015469 & 1.012104 & 0.015284 \\
\hline
\end{tabular}

CA: collapse affected grid percent, Grid (\%): grids in domain percent, FR: collapse affected grid (\%)/grids (\%). 
Table 3. Frequency ratio of topographical factors to collapse occurrences and results of the $P\left(A / B_{i}\right)$ obtained from the Conditional Probability model.

\begin{tabular}{|c|c|c|c|c|c|c|}
\hline Class & $\mathrm{CA}(\%)$ & Grid (\%) & $\mathrm{FR}$ & $P(A)$ & $P\left(B_{i}\right)$ & $P\left(A / B_{i}\right)$ \\
\hline \multicolumn{7}{|c|}{ Slope gradient } \\
\hline $0-3$ & 71.92454 & 46.53433 & 1.545623 & 0.032421 & 1.808421 & 0.017928 \\
\hline $3-6$ & 16.49871 & 12.88739 & 1.280221 & 0.007437 & 0.500831 & 0.014849 \\
\hline $6-9$ & 6.175495 & 9.894438 & 0.624138 & 0.002784 & 0.384518 & 0.007239 \\
\hline $9-12$ & 2.654541 & 8.672396 & 0.306091 & 0.001197 & 0.337027 & 0.00355 \\
\hline $12-15$ & 1.093769 & 7.022075 & 0.155762 & 0.000493 & 0.272892 & 0.001807 \\
\hline $15-18$ & 0.700504 & 5.164138 & 0.135648 & 0.000316 & 0.200689 & 0.001573 \\
\hline $18-21$ & 0.522306 & 3.712241 & 0.140698 & 0.000235 & 0.144265 & 0.001632 \\
\hline $21-24$ & 0.282659 & 2.559832 & 0.110421 & 0.000127 & 0.09948 & 0.001281 \\
\hline $24-27$ & 0.061448 & 1.6072 & 0.038233 & $2.77 \mathrm{E}-05$ & 0.062459 & 0.000443 \\
\hline $27-58.5$ & 0.086027 & 1.94596 & 0.044208 & $3.88 \mathrm{E}-05$ & 0.075624 & 0.000513 \\
\hline \multicolumn{7}{|l|}{ Slope aspect } \\
\hline Flat & 48.01524 & 22.43295 & 2.140389 & 0.021643 & 0.871791 & 0.024826 \\
\hline $\mathrm{N}$ & 0.995453 & 4.265246 & 0.233387 & 0.000448 & 0.165756 & 0.002707 \\
\hline $\mathrm{NE}$ & 5.272213 & 11.78929 & 0.447203 & 0.002376 & 0.458157 & 0.005187 \\
\hline $\mathrm{E}$ & 10.82709 & 9.83015 & 1.101416 & 0.00488 & 0.38202 & 0.012775 \\
\hline $\mathrm{SE}$ & 11.7488 & 11.468 & 1.024486 & 0.00529 & 0.44567 & 0.011883 \\
\hline $\mathrm{S}$ & 8.074229 & 10.14361 & 0.795992 & 0.003639 & 0.394202 & 0.009233 \\
\hline SW & 8.621113 & 10.50731 & 0.820487 & 0.003886 & 0.408336 & 0.009517 \\
\hline $\mathrm{W}$ & 2.310434 & 8.060875 & 0.286623 & 0.001041 & 0.313262 & 0.003325 \\
\hline NW & 2.875753 & 7.434744 & 0.386799 & 0.001296 & 0.28893 & 0.004486 \\
\hline $\mathrm{N}$ & 1.259678 & 4.06782 & 0.309669 & 0.000567 & 0.158084 & 0.003592 \\
\hline \multicolumn{7}{|c|}{ Topographical elevation } \\
\hline 1270-1300 & 5.198476 & 34.38717 & 0.151175 & 0.002343 & 1.336357 & 0.001753 \\
\hline $1300-1350$ & 12.8057 & 19.94596 & 0.64202 & 0.005772 & 0.775142 & 0.007447 \\
\hline $1350-1400$ & 8.240138 & 8.741031 & 0.942696 & 0.003714 & 0.339695 & 0.010934 \\
\hline $1400-1450$ & 12.29569 & 9.258899 & 1.327986 & 0.005542 & 0.35982 & 0.015403 \\
\hline $1450-1500$ & 37.00381 & 12.00461 & 3.082467 & 0.01668 & 0.466524 & 0.035753 \\
\hline $1500-1550$ & 14.64299 & 7.9581 & 1.840011 & 0.0066 & 0.309268 & 0.021342 \\
\hline $1550-1600$ & 9.708738 & 6.421032 & 1.512021 & 0.004376 & 0.249535 & 0.017538 \\
\hline $1600-1650$ & 0.104461 & 0.751714 & 0.138964 & $4.71 \mathrm{E}-05$ & 0.029213 & 0.001612 \\
\hline $1650-1700$ & 0 & 0.387154 & 0 & 0 & 0.015046 & 0 \\
\hline $1700-1730$ & 0 & 0.144327 & 0 & 0 & 0.005609 & 0 \\
\hline
\end{tabular}

CA: collapse affected grid percent, Grid (\%): grids in domain percent, FR: collapse affected grid $(\%) /$ grids $(\%)$.

The values of collapse susceptibility were classified using equal areas. The proportions are sorted from the smallest to the largest. This range of values is broken into five groups to represent the relative susceptibility in the study area.

\subsubsection{Multivariate model - logistic regression}

As it is well known, the logistic regression technique is a kind of multivariate statistical analysis, and due to its stepwise multivariate analysis nature, the multicollinearity is completely eliminated. On the other hand, the conditional probability approach usually suffers from multicollinearity problems. For this reason, more attention should be paid during the selection of appropriate conditioning factors for the relevant-dependent hazard.
Obviously, when applying such type of bivariate analyses, the expert opinions are more crucial and dominant.

Multiple regression analysis is the most common statistical method used in earth sciences, and expressed as a linear equation below.

$$
Y=b_{0}+b_{1} x_{1}+b_{2} x_{2}+\cdots+b_{n} x_{n}
$$

where $Y$ is the dependent variable representing the presence (1) or absence (0), $b_{0}$ the intercept of model, $b_{1}, \ldots, b_{n}$ the partial regression coefficients, $x_{1}, \ldots, x_{n}$ the independent variables.

As stated by Lee and Sambath (2006) logistic regression, which is a multivariate analysis model, is useful for predicting the presence or absence of a characteristic or outcome based on values of a set of predictor variables. Additionally, Yesilnacar 
Table 4. Frequency ratio of land-use and vegetation cover factors to collapse occurrences and results of the $P\left(A / B_{i}\right)$ obtained from the Conditional Probability model.

\begin{tabular}{|c|c|c|c|c|c|c|}
\hline Class & CA (\%) & Grid (\%) & $\mathrm{FR}$ & $P(A)$ & $P\left(B_{i}\right)$ & $P\left(A / B_{i}\right)$ \\
\hline \multicolumn{7}{|c|}{ Distance from roads } \\
\hline 0-300 & 21.82623 & 12.60865 & 1.731052 & 0.009838 & 0.489998 & 0.020078 \\
\hline $300-600$ & 22.26865 & 11.22047 & 1.984645 & 0.010038 & 0.436051 & 0.02302 \\
\hline $600-900$ & 20.69559 & 10.37025 & 1.995668 & 0.009329 & 0.40301 & 0.023148 \\
\hline $900-1200$ & 9.721027 & 9.588963 & 1.013773 & 0.004382 & 0.372647 & 0.011759 \\
\hline $1200-1500$ & 9.807054 & 9.169024 & 1.069585 & 0.004421 & 0.356327 & 0.012406 \\
\hline $1500-1800$ & 8.430626 & 8.296931 & 1.016114 & 0.0038 & 0.322436 & 0.011786 \\
\hline $1800-2100$ & 4.608578 & 7.461899 & 0.617615 & 0.002077 & 0.289985 & 0.007164 \\
\hline $2100-2400$ & 0.54074 & 5.274325 & 0.102523 & 0.000244 & 0.204971 & 0.001189 \\
\hline $2400-2700$ & 0.362541 & 4.548412 & 0.079707 & 0.000163 & 0.176761 & 0.000925 \\
\hline $2700-6624$ & 1.73897 & 21.46108 & 0.081029 & 0.000784 & 0.834022 & 0.00094 \\
\hline \multicolumn{7}{|c|}{ Distance from settlements } \\
\hline $0-500$ & 8.84847 & 4.231177 & 2.091255 & 0.003989 & 0.164432 & 0.024256 \\
\hline $500-1000$ & 14.78432 & 11.44056 & 1.292273 & 0.006664 & 0.444604 & 0.014989 \\
\hline $1000-1500$ & 21.18717 & 14.75396 & 1.436033 & 0.00955 & 0.573369 & 0.016656 \\
\hline $1500-2000$ & 14.686 & 14.87676 & 0.987178 & 0.00662 & 0.578142 & 0.01145 \\
\hline $2000-2500$ & 13.51235 & 15.57937 & 0.867324 & 0.006091 & 0.605447 & 0.01006 \\
\hline $2500-3000$ & 13.89333 & 15.95569 & 0.870745 & 0.006263 & 0.620071 & 0.0101 \\
\hline $3000-3500$ & 8.774733 & 10.94243 & 0.8019 & 0.003955 & 0.425246 & 0.009301 \\
\hline $3500-4000$ & 3.232149 & 7.370599 & 0.438519 & 0.001457 & 0.286437 & 0.005086 \\
\hline $4000-4500$ & 1.08148 & 4.128331 & 0.261965 & 0.000487 & 0.160436 & 0.003039 \\
\hline $4500-4874$ & 0 & 0.721138 & 0 & 0 & 0.028025 & 0 \\
\hline \multicolumn{7}{|l|}{ NDVI } \\
\hline$-0.9-0.1$ & 62.64594 & 44.69421 & 1.401657 & 0.028238 & 1.73691 & 0.016258 \\
\hline $0.1-0.3$ & 25.15669 & 31.81309 & 0.790766 & 0.01134 & 1.236323 & 0.009172 \\
\hline $0.3-0.6$ & 12.14207 & 23.35152 & 0.519969 & 0.005473 & 0.907488 & 0.006031 \\
\hline $0.6-0.83$ & 0.055303 & 0.141191 & 0.391688 & $2.49 \mathrm{E}-05$ & 0.005487 & 0.004543 \\
\hline
\end{tabular}

CA: collapse affected grid percent, Grid (\%): grids in domain percent, FR: collapse affected grid (\%)/grids (\%).

and Topal (2005) mentioned that the key to logistic regression is that the dependent variable is dichotomous. The independent variables in this model are predictors of the dependent variable and can be measured on a nominal, ordinal, interval or ratio scale. The datasets, in vector format, were converted into raster format. The conversion of parameters from nominal to numeric can be done through the creation of dummy variables or by coding and ranking the classes based on the relative percentage of the area affected by occurrence. The two methods are similar but the latter is to be preferred for two reasons: (i) it avoids the creation of an excessively high number of dummy variables and (ii) allows consideration of the so-called 'previous knowledge' of susceptibility (Carrara 1983; Yesilnacar and Topal 2005). In this study, each class in the geology map was ranked based on the latter technique.

At the beginning of the analysis, a map showing the area affected by collapse and factor maps in raster format were converted into ASCII format. Statistical software (SPSS 10.0) was then used to estimate the correlation between collapse event and collapse affecting factors. An equation predicting the collapse occurrence was obtained as following

$$
\begin{aligned}
Y= & 8.112+\left(A S P E C T^{(*)}\right)+\left(-0.0483^{*} F A U L T\right) \\
& +\left(0.0396^{*} D R A I N\right)+\left(-0.0401^{*} S L O P E\right) \\
& +\left(-0.0331^{*} S P I\right)+\left(0.0296^{*} T W I\right) \\
& +\left(-0.0302^{*} R O A D\right)+\left(-0.0291^{*} S E T T L\right) \\
& +\left(-0.0013241^{*} N D V I\right)+\left(-0.0091^{*} E L E V\right)
\end{aligned}
$$

${ }^{(*)}$ logistic regression coefficients of categorical data of 'ASPECT' can be seen in table 5 .

In order to calculate the probability of collapse occurrence in each grid cell, the following equation was implemented (equation 10).

$$
p=\frac{1}{1+e^{-Y}} .
$$

Finally, susceptibility map was obtained by converting the file into the raster format (figure 12b). 
Table 5. Logistic regression coefficients of categorical data.

\begin{tabular}{lr}
\hline Category & Coefficient \\
\hline Slope aspect & \\
Flat & 0.017124 \\
N & -0.000122 \\
NE & 0.000411 \\
E & 0.009163 \\
SE & 0.007231 \\
S & 0.000631 \\
SW & 0.000742 \\
W & -0.000112 \\
NW & -0.000103 \\
N & -0.000237 \\
\hline
\end{tabular}

\subsubsection{Soft computing model - artificial neural networks}

Soft computing techniques have the ability to handle imprecise and fuzzy data; they can work with continuous, categorical and binary data without violating any assumptions. As assessment of probability for collapse is performed through the forecast of future events from experience of past collapses, it may be considered an ideal application for soft computing techniques.

As mentioned previously, ANNs is one of the most applied soft computing techniques in recent scientific literature (Negnevitsky 2002; Nefeslioglu et al. 2008; Ramakrishanan et al. 2008). ANNs consist of a large class of different architectures. In many cases, the issue is approximating a static nonlinear, mapping $f(\mathbf{x})$ with a neural network $f(\mathbf{x})_{N N}$, where $\mathbf{x} \in \mathbf{R}^{K}$. There are many kinds of ANN models, among which the back propagation (BP) model is the most widely used, and it is an instructive training model. It is accepted that the most useful neural networks in prediction and decision algorithm are $\mathrm{BP}$ and radial basis function $(\mathrm{RBF})$ networks. In this paper, $\mathrm{BP}$ algorithm, created by generalizing the Widrow-Hoff learning rule to multiple-layer networks and nonlinear differentiable transfer function, is used. A back propagation consists of an input layer, several hidden layers, and output layers. All of those layers may contain multiple nodes (Yilmaz and Yüksek 2008, 2009).

The inputs $x_{n}, n=1, \ldots, n$, to the neuron are multiplied by weights $w_{n i}$ and summed up together with the constant bias term $Q_{i}$. The resulting $n_{i}$ is the input to the activation function $y$. The activation function was originally chosen to be a relay function, but for mathematical convenience a hyperbolic tangent $(\tan h)$ or a sigmoid function is most commonly used. Connecting several nodes in parallel and series, an MLP network is formed. A typical network is shown in figure 13 .

MatLab 7.0 was used for training and testing for the neural networks. A three-layer feed-forward network that consists of an input layer (10 neurons), one hidden layer (21 neurons) and one output layer was used as a network structure of 10-21-1 (figure 13). In order to find the number of hidden layer nodes, equation (11) proposed by HechtNielsen (1987) was used.

$$
N_{h}=2^{*} N_{i}+1
$$

where $N_{i}$ is the number of input nodes and $N_{h}$ is the number of hidden nodes.

Initial weight range is also an important parameter influencing the convergence of learning rule. In this study, weights were randomly initialized in a small range of -0.25 to 0.25 as proposed by

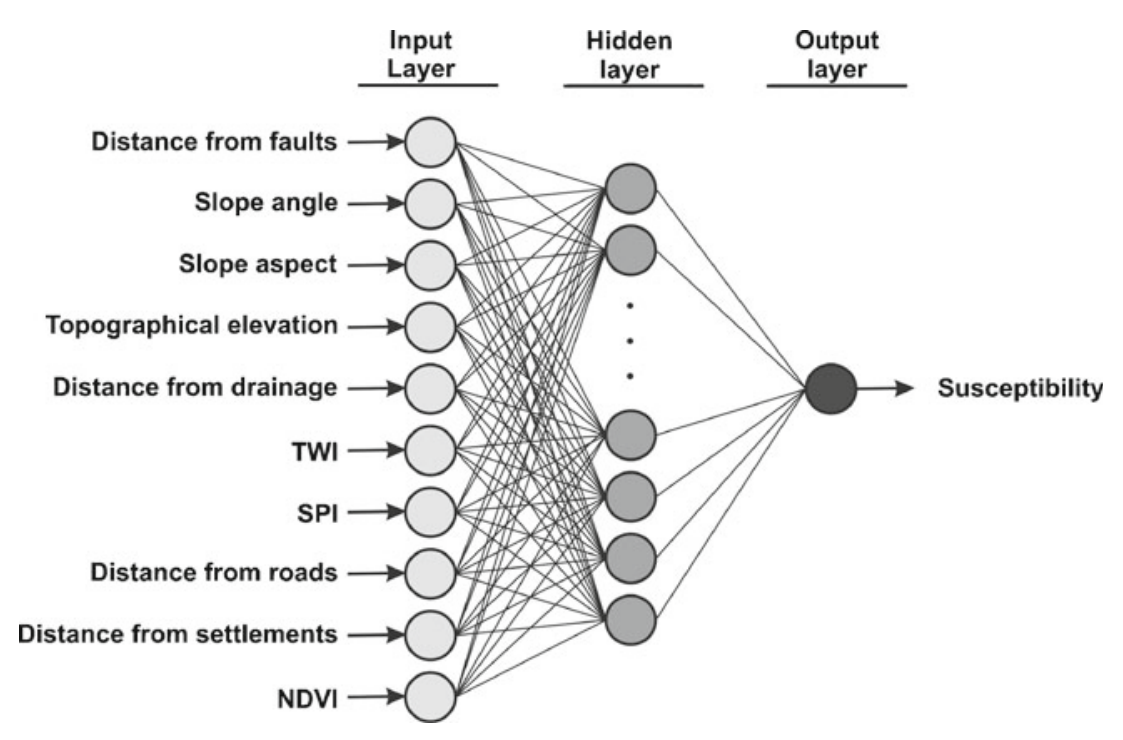

Figure 13. Neural network structure used in the study. 
Kavzoglu (2001). Kavzoglu (2001) has also suggested that the minimum number of training samples should be more than $30^{*} N_{i}^{*}\left(N_{i}+1\right)$ where $N_{i}$ is the number of input nodes. Learning and momentum parameters were set as follows as proposed by Foody et al. (1996). Almost 18,000 pixels were randomly selected from the two classes (collapse and non-collapse) as training samples, and parameters were then adjusted as below.

Learning parameters: 0.1.

Momentum parameters: 0.9 .

Networks training function: variable learning rate with momentum (traingdx).

Activation (transfer) function for all layers: tansig.

Moreover, training areas were checked in the field for accuracy and completeness. As in many other network training methods, models and parameters were used to be able to reach minimum Root Mean Square Error (RMSE) values. RMSE goal for stopping criterion was set to 0.1 . After the network goal was reached, the whole study area was fed into the network in order to estimate the collapse susceptibility. The set of susceptibility values obtained in each grid cell were then converted to raster file in GIS environment, and collapse susceptibility map was produced (figure 12c).

\subsection{Validation of the models}

The collapse susceptibility maps can be tested using the known collapse locations. Validation was performed by comparing the known collapse location data, which were not included in the susceptibility

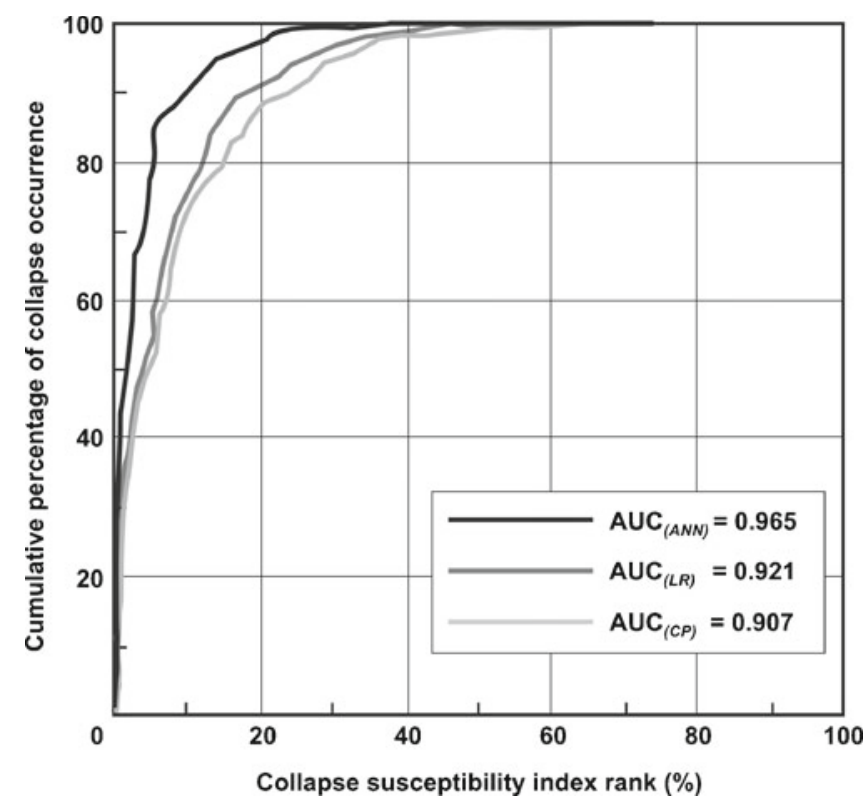

Figure 14. Area under curve (AUC) representing the quality of the models used. analyses, with the susceptibility map obtained. The area under curve (AUC) is a good indicator to evaluate the prediction performance of the model, and the largest AUC, varying from 0.5 to 1.0, is the most ideal model (Swets 1988; Yesilnacar and Topal 2005). By the use of 100 subdivisions of CSI values of all cells in the study area and cumulative percentage of collapse occurrence in the classes, curves were drawn to calculate AUC (figure 14). Additionally, in order to evaluate the receiver operating characteristic (ROC) curve for the conditional probability results, the resultant probabilities were stretched between 0 and 1 . The obtained values of AUC from the four mapping models are given in figure 14. Although ANN is the most accurate method, the results for all three used methodologies do not show significant difference; i.e., all three approaches lead to very similar results and, therefore, can be used in collapse susceptibility mapping. Moreover, validation by field investigations was also performed by comparing the known collapse location data with the classes of collapse susceptibility in maps. The results obtained from field observation were also found to be harmonious with results of AUC.

\section{Results and discussion}

The use of bivariate, multivariate and soft computing methods such as conditional probability (CP), logistic regression (LR) and artificial neural networks (ANN) models in GIS based collapse susceptibility mapping in an area from Sivas basin (Turkey) was compared and discussed in this article. Collapse-related factors, directly or indirectly related to the causes of collapse occurrence, such as distance from faults, slope angle and aspect, topographical elevation, distance from drainage, topographic wetness index (TWI), stream power index (SPI), normalized difference vegetation index (NDVI) by means of vegetation cover, distance from roads and settlements, were used in susceptibility analyses, and the following results were obtained.

- Analyses of distance from lineaments (figure 4b) showed that frequency ratios greater than 1 were obtained at a distance lower than $1000 \mathrm{~m}$, indicating a high probability of collapse occurrence (figure 8; table 1). It can be seen that as the distance from faults decreases, the number of collapses increase, because the weathering and fracturing of rocks increase with increasing proximity to the lineament.

- Frequency ratios of distance to drainage (figure 5a) indicated a low collapse probability at a distance lower than $500 \mathrm{~m}$ (figure 9a; table 2). 
This can be explained as the first $500 \mathrm{~m}$ refers to the river bed where the occurrence of very deep erosion in gypsum did not allow the development of any karstic structure.

- As a measure of erosive power of the overland flow, frequency ratio values were found to be greater than 1 in areas having a lower SPI values (figure $5 \mathrm{~b}$ ) than 0.50 (figure $9 \mathrm{~b}$; table 2). The parameter SPI is a measure of the erosional power of water related with the channel geometry. Therefore, the geomorphic features derived from gypsum karst, as could be clearly understood, could be suppressing due to the possible high erosion rates sourced from high stream power.

- The higher probabilities of collapse occurrence were found in cells having the higher TWI value (figure $5 \mathrm{c}$ ) which is a measure of moisture (figure 9c; table 2).

- It has been observed that most of the recorded collapses occurred in areas with a slope less than $6^{\circ}$. Surficial cover materials are generally removed by the surface water flows where the slopes are steep. As seen in table 3, showing the distribution of collapses in relation to slope, it can be concluded that the slope factor has an inverse effect on the development of collapse (figure 10a).

- In the case of the relationship between collapse occurrence and aspect (figure 6b), collapses were most abundant on east-facing and flat areas (figure 10b; table 3) depending on the regional/ local groundwater flow regime.

- Topographical elevation map (figure 6c) showed that collapses occur in areas with an elevation between 1350 and $1600 \mathrm{~m}$ as seen in figure 10(c). Table 3 shows the relationships between collapse occurrence and topographical elevation. It may be concluded that the dolines occur in relatively flat areas, because the hilly and mountainous areas generally have high slope angles.

- Analyses were carried out to assess the influence of road lines on collapse occurrence. For this purpose, the proximity to road lines was identified by buffering (figure 7a). For distances lower than $\sim 1000 \mathrm{~m}$, frequency ratio values higher than 1 were obtained (table 4), indicating the high collapse occurrence probability (figure 11a). This result means that the collapse occurrence probability increases with decreasing proximity to the roads. The main road crossing the study area from SW to NE is especially important for transportation from the west of Turkey to the east. It can be thought that vibrations sourced from high load of traffic may be triggering the collapse event in very young doline locations.

- In order to analyse the influence of the proximity to the settlement area, a buffering method was used (figure $7 \mathrm{~b}$ ). In the case of the relationship between collapse occurrence and distance from settlement, it was seen that as the distance increases, collapse frequency decreases (figure 11b; table 4). At a distance lower than $\sim 1500 \mathrm{~m}$, frequency ratio was higher than 1 , indicating a high probability of collapse occurrence. This can be attributed to the human use effect such as stresses induced by foundation loadings and live loadings, human-made sources of water, lowering of the groundwater by dewatering and vibrations from adjacent site activities. This parameter was found as affecting factor in collapse event in very young doline locations, particularly.

- NDVI is a measure of surface reflectance and gives a quantitative estimate of the vegetation growth and biomass (Hall et al. 1995). Satellite maps of vegetation show the density of plant growth over the entire globe. Very low values of NDVI (0.1 and below) correspond to barren areas of rock, sand or snow. Moderate values represent shrub and grassland (0.2 to 0.3 ), while high values indicate temperate and tropical rainforests (0.6 to 0.8) (Weier and Herring 2005). Using the satellite image of Landsat Thematic Mapper (TM), the NDVI was taken into consideration as a collapse-related factor (figure 7c). The relationship between collapse occurrence and NDVI can be seen in table 4 . The results show that collapse probability increases with decreasing of NDVI. It was observed that the collapses were focused in rocky barren areas with an NDVI value smaller than 1 (figure 11c).

The results of this study showed that the map obtained from ANN model look like having a better accuracy than the conventional statistical methods, however all the models were found having relatively similar accuracies. The main problem in the use of ANN and LR is time-consuming input process, calculations and output process. Because they require conversion of data used in analyses into ASCII or other formats, and it is also very hard to process the large amount of data in statistical software. As stated by Yilmaz (2008a, 2008b) "It should not be forgotten that 'simple is the best' in engineering applications", that's why the Conditional Probability Model can be used as an essential tool in the assessment of collapse susceptibility and the preparation of maps. Moreover, ANNs are one of a large array of black-box prediction methods. The main disadvantage of black-box methods is that the causal relationships can not be seen, whereas regression methods allow quantification of the importance of the factors. This paper has also an extra value with its comparative nature, because the use of conventional (conditional probability, logistic regression) and soft computing (ANN) in 
collapse susceptibility mapping were compared for the first time.

Preparation of collapse susceptibility maps will help the planners and engineers for choosing suitable locations to implement developments. These results can be used as basic data to assist landuse planning, but the methods used are valid for generalized planning and assessment purposes, although they may be less useful at the site-specific scale.

\section{Acknowledgements}

The authors are deeply grateful to the anonymous reviewers for their very constructive comments and suggestions which led to the improvement of the quality of the paper. Authors also thank Asst. Dr Hakan A Nefeslioglu (Cumhuriyet University, Sivas - TURKEY) for his useful comments.

\section{References}

Bruno E, Calcaterra D and Parise M 2008 Development and morphometry of sinkholes in coastal plains of Apulia, southern Italy. Preliminary sinkhole susceptibility assessment; Eng. Geol. 99 198-209.

Carrara A 1983 Multivariate models for landslide hazard evaluation; Math. Geol. 15(3) 403-426.

Clerici A, Perego S, Tellini C and Vescovi P 2002 A procedure for landslide susceptibility zonation by the conditional analysis method; Geomorphology 48 349-364.

Foody G M, Lucas R M, Curran P J and Honzak M 1996 Estimation of the areal extend of land cover classes that only occur at a sub-pixel level; Canadian J. Rem. Sens. $22432-438$.

Forth R A, Butcher D and Senior R 1999 Hazard mapping of karst along the coast of the Algarve, Portugal; Eng. Geol. 52 67-74.

Galve J P, Bonachea J, Remondo J, Gutiérrez F, Guerrero J, Lucha P, Cendrero A, Gutiérrez M and Sánchez J A 2008 Development and validation of sinkhole susceptibility models in mantled karst settings. A case study from the Ebro valley evaporite karst (NE Spain); Eng. Geol. 99 185-197.

Gokceoglu C, Sonmez H, Nefeslioglu H A, Duman T Y and Can T 2005 The 17 March 2005 Kuzulu landslidesusceptibility map of its near vicinity; Eng. Geol. 81 65-83.

Guerrero J, Gutiérrez F, Bonachea J and Lucha P 2008 A sinkhole susceptibility zonation based on paleokarst analysis along a stretch of the Madrid-Barcelona high-speed railway built over gypsum- and salt-bearing evaporites (NE Spain); Eng. Geol. 102 62-73.

Hall F G, Townshend J R and Engman E T 1995 Status of remote sensing algorithms for estimation of land surface state parameters; Rem. Sens. Environ. 51 138-156.

Hecht-Nielsen R 1987 Kolmogorov's mapping neural network existence theorem; Proceedings of 1st IEEE International Conference on Neural Networks, San Diego, CA, USA, pp. 11-14.

Karacan E and Yilmaz I 1997 Collapse dolines in the Miocene gypsum: An example from SW Sivas (Turkey); Environ. Geol. 29(3/4) 263-266.
Kaufman O and Quinif Y 2002 Geohazard map of covercollapse sinkholes in the 'Tournaisis' area, southern Belgium; Eng. Geol. 65 117-124.

Kavzoglu T 2001 An investigation of the design and use of feed-forward artificial neural networks in the classification of remotely sensed images; Thesis (PhD), University of Nottingham, School of Geography, 306p.

Klimchouk A and Andrejchuk V 2005 Karst breakdown mechanisms from observations in the gypsum caves of the Western Ukraine: Implications for subsidence hazard assessment; Environ. Geol. 48 336-359.

Lee S and Talib J A 2005 Probabilistic landslide susceptibility and factor effect analysis; Environ. Geol. 47 982-990.

Lee S and TuDan N 2005 Probabilistic landslide susceptibility mapping in the Lai Chau province of Vietnam: Focus on the relationship between tectonic fractures and landslides; Environ. Geol. 48 778-787.

Lee S and Sambath T 2006 Landslide susceptibility mapping in the Damrei Romel area, Cambodia using frequency ratio and logistic regression models; Environ. Geol. 50(6) $847-856$.

Menard S 1995 Applied logistic regression analysis; Sage University Paper Series on Quantitative Applications in Social Sciences, 106 Thousand Oaks, California, p. 98.

Nefeslioglu H A, Gokceoglu C and Sonmez H 2008 An assessment on the use of logistic regression and artificial neural networks with different sampling strategies for the preparation of landslide susceptibility maps; Eng. Geol. 97(3-4) 171-191.

Nefeslioglu H A, San B T, Gokceoglu C and Duman T Y 2012 An assessment on the use of Terra ASTER L3A data in landslide susceptibility mapping; Int. J. Appl. Earth Observ. Geoinform. 14 40-60.

Negnevitsky M 2002 Artificial Intelligence - A Guide to Intelligent Systems; Addison - Wesley Co., Great Britain, $394 \mathrm{p}$.

Ramakrishnan D, Ghosh M K, Vinuchandran R and Jeyaram A 2005 Probabilistic techniques, GIS and remote sensing in landslide hazard mitigation: A case study from Sikkim Himalayas, India; Geocarto Int. 20(4) 1-6.

Ramakrishanan D, Singh T N, Purwar N, Badre K S, Gulati A and Gupta S 2008 Artificial neural network and liquefaction susceptibility assessment: A case study using the 2001 Bhuj Earthquake data, Gujarat, India; Comp. Geosci. 12 491-501.

Singh T N, Kanchan R, Verma A K and Singh S 2003 An intelligent approach for prediction of triaxial properties using unconfined uniaxial strength; Mining Eng. J. 5(4) $12-16$.

Swets J A 1988 Measuring the accuracy of diagnostic systems; Science 240 1285-1293.

Tolmachev V T, Pidyashenko S E and Balashova T A 1999 The system of antikarst protection on railways of Russia; In: Hydrogeology and Engineering Geology of Sinkholes and Karst (eds) Barry B, Pettit-Arthur J and Herring J G (Rotterdam: A.A. Balkema), pp. 423-429.

Weier J and Herring D 2005 Measuring vegetation (NDVI and EVI). Earth Observatory Library of NASA, http:// earthobservatory.nasa.gov/Library/MeasuringVegetation/.

Wilson J P and Gallant J C 2000 Terrain Analysis Principles and Applications; John Wiley and Sons, Inc., Canada.

Yesilnacar E and Topal T 2005 Landslide susceptibility mapping: A comparison of logistic regression and neural networks method in a medium scale study, Hendek region (Turkey); Eng. Geol. 79 251-266.

Yilmaz I 2007 GIS based susceptibility mapping of karst depression in gypsum: A case study from Sivas basin (Turkey); Eng. Geol. 90(1-2) 89-103. 
Yilmaz I 2008a Discussion on "Development and morphometry of sinkholes in coastal plains of Apulia, southern Italy. Preliminary sinkhole susceptibility assessment" by E. Bruno, D. Calcaterra, M. Parise [Engineering Geology 99 (2008) 198-209]; Eng. Geol. 101 283-284.

Yilmaz I 2008b A case study for mapping of spatial distribution of free surface heave in alluvial soils (Yalova, Turkey) by using GIS software; Comp. Geosci. 34(8) 993-1004.

Yilmaz I 2009 Landslide susceptibility mapping using frequency ratio, logistic regression, artificial neural networks and their comparison: A case study from Kat landslides (Tokat-Turkey); Comp. Geosci. 35(6) 11251138.
Yilmaz I and Karacan E 2005 Slaking durability and its effect on the doline occurrence in the gypsum; Environ. Geol. 47(7) 1010-1016.

Yilmaz I and Yüksek A G 2008 An example of artificial neural network application for indirect estimation of rock parameters; Rock Mech. Rock Eng. 41(5) 781-795.

Yilmaz I and Yüksek A G 2009 Prediction of the strength and elasticity modulus of gypsum using multiple regression, ANN, ANFIS models and their comparison; Int. J. Rock Mech. Mining Sci. 46(4) 803-810.

Zhou W, Beck B F and Adams A 2003 Application of matrix analysis in delineating sinkhole risk areas along highway (I-70 near Frederick, Maryland); Environ. Geol. 44 834-842. 